\title{
Assessment of Progress in Capacity Building of HIV/AIDS Supply Chain Workforce in Nigeria
}

\author{
Sunday O Aguora ${ }^{1 *}$, Azuka C Oparah ${ }^{2}$, Edith C Okechukwu ${ }^{1}$, Jeffrey S Soni ${ }^{2}$ \\ ${ }^{1}$ School of Public Health, Texila American University, Georgetown, Guyana, South America \\ ${ }^{2}$ Department of Pharmacy and Pharmacy Practice, Faculty of Pharmacy, University of \\ Benin, Benin City, Nigeria
}

\begin{abstract}
This study on assessment of progress in capacity building of HIV/AIDS supply chain workforce in Nigeria included research objectives, questions, and hypothesis. A pre-tested self-completion structured questionnaire was administered to participants (422) with a response rate of 396 (93.8\%). The reliability statistics showed the questionnaire is less reliable $(\alpha=0.237)$. Notable progress includes donor agencies interventions contributing considerably to capacity building of government personnel and adequate capacity at the national level 396 (100.0), the institutionalization of capacity development at all levels through National Product Supply Chain Management Programme, Procurement and Supply Management Technical Working Groups, and Logistics Management Coordinating Unit 292 (73.7) and demonstrable capacity in key supply chain functions 259 (65.4). The study revealed substantial progress in capacity building of the HIV/AIDS supply chain workforce, evident with the institutionalization of capacity building and demonstrable capacity in the key supply chain functions. More so, master trainers from the government are not always part of the facilitators and involved in capacity building, needs assessment does not always precede capacity building, the inadequate pool of master trainers, fellowship training program is not recognized, and pre-service training has not been institutionalized. Chi-square statistics revealed that the extent of progress in capacity building is a significant factor of HIV/AIDS supply chain workforce capacity ( $p<0.05)$. There is a need to develop manuals, policies, and procedures to ensure sustained progress in capacity building, needs assessment precedes capacity building, more training conducted to ensure an adequate pool of master trainers in the public sector and their participation in future capacity building interventions.
\end{abstract}

Keywords: Capacity building, HIV/AIDS supply chain, Progress, Workforce.

\section{Introduction}

Effective and efficient capacity building supports national health plans and health care system development [1]. Developing countries have rarely had sufficient skilled human resources for health, and competence gaps exist with categories of healthcare practitioners involved in the HIV/AIDS supply chain. This is further strained due to limited training opportunities and resources for capacity building, principally for the supply chain workforce in the hard-to-reach health facilities. Notwithstanding, the lack of an adequate supply chain workforce to support scale-up of services has been a major constraint to HIV/AIDS program. These underpin the fact that supply chain management systems are weak, yet they are essential for the successful scale-up of treatment programs [2].

Previous study [1] has shown that a lot is still desired to ensure an effective and efficient HIV/AIDS supply chain system that will deliver health products to intended beneficiaries 
on time, return critical information to decisionmakers for planning purposes, overcome pressure of increased volumes due to programs scale up and new initiatives, prevent supply chain management challenges and support the achievement of the Nigeria's strategic health objectives. Therefore, ensuring adequate institutional and human resources to meet the challenges of HIV/AIDS in sub-Saharan Africa into the future requires visionary strategic planning and investments in capacity building [1]. Effective capacity building will ensure a well-performing workforce that works in responsive, fair, and efficient ways to provide quality services and achieve the best health outcomes, given available resources and circumstances $[3,4,5]$.

Nonetheless, it has been reported that there is usually a direct link between efficient health system governance and promising workforce outputs, with positive effects on overall health outcomes [6]. There are growing concerns that Nigeria's health workforce crisis is linked to the poor states of health governance [6, 7]. Hence tools and guidelines are needed to assist health system decision-makers in monitoring and assessing workforce development using standard definitions, indicators, and measures $[8,9]$. Recognizing the diversity of stakeholders and complexity of health systems is crucial to ensure that evidence-based guidelines are tested with requisite humility and without rigid adherence to models dominated by a limited number of disciplines [10, 11]. Health Policy and Systems Research (HPSR) calls for greater involvement of local actors, including policymakers, civil society, and researchers, in decisions that are made around health systems strengthening [12]. A number of health systems have failed typically due to their lack of resilience and capacity to respond to pressing workforce and larger population health needs [13].

Consequently, the present study seeks to assess progress in capacity building of the HIV/AIDS supply chain workforce in Nigeria.

\section{Methods}

\section{Study Design/Selection of the Area}

A Cross-sectional observational design was used for the study. The study was carried out in Abuja, Nigeria's Federal Capital Territory (FCT), North-Central geo-political zone. The Federal Capital Territory was created in 1976 and had a population of 3,564,100 (2016 estimate) and covers about 8000 square kilometers. Abuja is the fastest-growing and wealthiest city on the African continent and one of the fastest-growing cities in the world [14, 15]. The choice of Abuja as the location for data collection to address the research questions is because most of the health supply chain organizations have their offices in Abuja from where they carry out their HIV/AIDS supply chain functions around the country. Abuja is the administrative and political centre of Nigeria and also the location (as the capital of Nigeria and seat of power) for policy development, coordination, and monitoring of implementation.

\section{Sample Size Determination}

Cochran's formula

$$
\left(\mathrm{n}_{0}=\mathrm{z}^{2} \mathbf{p q} / \mathrm{e}^{2}\right)
$$

was used to determine the sample size for this study [16].

$$
\begin{aligned}
\mathrm{n}_{0}= & \text { sample size } \\
\mathrm{z}= & 1.96 \text { (selected critical value of } \\
& \text { desired confidence level) } \\
\mathrm{p}= & 0.5 \text { (assuming the maximum } \\
& \text { variability, which is equal to } 50 \%) \\
q= & 1-\mathrm{p} \\
\mathrm{e}= & 0.05( \pm 5 \% \text { desired level of } \\
& \text { precision at } 95 \% \text { confidence level) } \\
\mathrm{n}_{0}= & (1.96)^{2}(0.5)(0.5) /(0.05)^{2} \\
\mathrm{n}_{0}= & 384.16
\end{aligned}
$$

An overage (10\% of the calculated sample size) was added to the sample size to make provision for drop out, non-response, incomplete response, and late response to enable the realization of the minimum required sample size. 


\section{Sampling Technique}

This study involved HIV/AIDS supply chain workforce (422) working in the public sector, private sector, faith-based organization, nongovernmental organization, and donor agency selected using a random sampling technique. Study participants included those with a minimum of bachelor's degree qualification, and who have spent at least 2 years in their organization, agreed to read and signed the consent form, and did not participate in the pilot. Whereas other supply chain workforce (e.g., Malaria, Tuberculosis, etc.), HIV/AIDS supply chain workforce that have spent less than 2 years in their organization, without at least bachelor's degree qualification, participated in the pilot and declined to sign the consent form were excluded from participating in the study.

\section{Data Collection}

Data were collected from the field using a structured self-completion questionnaire. The purpose of the study and questionnaire were explained to the participants. Participation was voluntary, and identity was kept confidential and anonymous. Participants read and signed the consent form before joining the study and free to withdraw at any point without consequences. The questionnaire had fifteen (15) questions; all items were anchored on a Likert scale of 1-5 (5-point scale) with which relevant information in the area of sociodemographic characteristics and progress in capacity building of HIV/AIDS supply chain workforce were obtained. The questionnaire required about 10 minutes to complete. The questionnaire was developed based on relevant literature and empirical studies to ensure construct validity. The questionnaire was amended based on the reviewer's feedback and pilot result to ensure content validity. The offices of the Nigeria HIV/AIDS supply chain organizations in Abuja were visited to administer the questionnaire without identifiers. Participants who could not complete it at the time of the visit were allowed to complete and return the questionnaire at a later date to eliminate social response bias. Ethical approval was granted by the National Health Research Ethics Committee of Nigeria (NHREC).

\section{Data Analysis}

Completed and retrieved questionnaires were reviewed for accuracy, completeness, and consistency. The questionnaires were thereafter numbered serially and coded. Each questionnaire was entered on the excel template. The final entries were rechecked for accuracy, followed by data analysis. Reliability, frequency, descriptive statistics were done using Statistical Package for Social Sciences (SPSS) version 22.0 (SPSS Inc., Chicago, Illinois, USA), and inferential statistics were performed. Students-test, Chi-square, and oneway analysis of variance (ANOVA) were carried out with the aid of Graph Pad In stat version 3.0. $\mathrm{P}$ values $<0.05$ were considered significant.

\section{Results and Discussion}

The survey had a response rate of 396(93.8\%). Table 1. Socio-demographic characteristics of participants, table 2 . Percentage frequency of progress in capacity building of HIV/AIDS supply chain workforce, table 3. Reliability analysis of progress in capacity building of HIV/AIDS supply chain workforce, table 4. Effect of socio-demographic characteristics on progress in capacity building and table 5. Relationship between progress in capacity building and HIV/AIDS supply chain workforce capacity.

In the present study, the socio-demographic characteristics of the participants showed that the age of most $328(82.9 \%)$ of the participants is between 30 and 49 years, majority male $275(69.4 \%)$, years of experience in the HIV/AIDS supply chain between 8 and 15 years $241(60.8 \%)$ and more than half with master's degree as highest educational qualification 256 (64.6\%). The participants 
have considerable experience, knowledge, and understanding of HIV/AIDS supply chain management, thus assuring credibility and quality of the research outcomes. The participants were drawn from all sectors and the majority from non-governmental organizations 207(52.3\%). This depicts the involvement of diverse stakeholders, perspectives, expertise, and capacity needed to drive supply chain policy development and implementation for an effective and efficient HIV/AIDS supply chain system.

The study revealed substantial progress in capacity building of the HIV/AIDS supply chain workforce to enable the provision of quality services, and personnel in Nigeria's HIV/AIDS supply chain have demonstrated capacity to some extent in the key supply chain functions. In a previous study, [17] reported adequate capacity at the national level, especially within the private sector.

However, need assessment does not always precede capacity-building interventions. This suggests that capacity building may not be tailored to need or provided to the right personnel and might fail to address competency gaps. This might explain partly the reason various training and capacity building interventions implemented have not translated to improved workforce performance as supply chain management challenges are still inherent in the Nigeria HIV/AIDS system (e.g., stockouts, wastages due to expiries/damage, unaccounted stock, inaccurate forecast and unimplemented quality control plans). If appropriate trainings and capacity-building programs are not administered to appropriate staff, it may impede the country's progress in capacity building and sustainability.

Similarly, the study revealed that donor agencies interventions have contributed considerably to the capacity building of government personnel across all levels, and there is adequate capacity at the national level, especially within the donor agencies, nongovernmental organizations (NGOs), and private sector. This finding is consistent with the report of a previous study [18] that capacity building in developing countries has been externally driven by implementing partners through donor funding, related to project implementation, and often has resulted in the disempowerment of local organizations rather than promoting local ownership and sustainability. It also agrees with an earlier report [17] that donor-funded programme has built the capacity of Nigerians on supply chain management through in-service and pre-service training and contributed significantly to capacity building for the locals as well as incountry infrastructural upgrades.

The greater proportion of the participants disagreed that there is an adequate pool of master trainers in the HIV/AIDS supply chain system. This suggests that more training is required to ensure the availability of a sufficient pool of resources within the public sector that can drive the country's supply chain functions, as well as develop HIV/AIDS human resources capacity at the health facility, LGA, state, and country-level which is fundamental for progress. An adequate pool of knowledgeable human resources is paramount to obtaining accurate and timely logistics data to ensure health commodity security, effective and sustainable supply chains [19].

An equal number of participants agreed and disagreed on the extent of progress in the fellowship training program to enhance leadership and management. The link indicates that the fellowship training program is not yet recognized as an effective capacity-building strategy in Nigeria. The key objective of the fellowship program is to increase the number of workforces equipped with knowledge and skills of program leadership and management for effective program implementation and sustainability [20]. It is relevant in addressing specific contextual institutional managementrelated problems and has been implemented with huge success in Uganda [20]. 
A little above average (56.6\%) of the participants disagreed that master trainers from government are always part of the facilitators and involved in the implementation of capacitybuilding interventions. This finding further suggests that a lot still needs to be done to ensure a sustainable system and prepare for the long-term burden of HIV/AIDS, especially in view of the envisaged decreasing PEPFAR funding and eventual handover of responsibilities to national governments [21]. The present study is in disagreement with a previous study [12] that reported the need for more involvement of local actors in decisions and activities related to the funding of health policy research and health systems strengthening. It has been observed that health systems often fail owing to a lack of capacity and resilience to respond to health workforce needs and larger population health needs [13]. It is believed that additional attention to the principles of ownership and sustainability will ensure effective transfer of capacity building programs to the government.

The study further revealed that HIV/AIDS supply chain capacity development had been institutionalized at national, state, and LGA levels through National Product Supply Chain Management Programme (NPSCMP), Procurement and Supply Management Technical Working Group (PSM TWG), and Logistics Management Coordinating Unit (LMCU). The finding agrees with a previous report [17] on the establishment and functional HIV/AIDS supply chain management-specific coordination structures; National Product Supply Chain Management Programme (NPSCMP) at the national level, Procurement and Supply Management Technical Working Groups (PSM TWGs) at the national, regional and state levels and Logistics Management Coordinating Unit (LMCU) at the state and local government area level with LMCU responsible for data management and activities of the unit said to be improving logistics data availability, visibility, quality and use for decision.

More than half of the participants disagreed that pre-service training has been institutionalized in the schools of Pharmacy, Laboratory Sciences, and Health Technology to address competency gaps despite past efforts adjudged successful. In Nigeria, Supply Chain Management System (SCMS) implemented a three-pronged approach; pre-service training, in-service training, and e-learning that ensured the availability of the health workforce with critical supply chain management (SCM) skills for continued patient access to life-saving medicines [22]. The program was successful due to stakeholder engagement and buy-in, strategic use of existing educational structures, professional bodies, and the Ministry of Health's commitment. The current study's finding disagrees with earlier work [17] that reported the institutionalization of pre-service training in the schools of Pharmacy, Laboratory Sciences, and Health Technology as a means of addressing the supply chain competencies gap. Pre-service education allows students to develop their competencies in the supply chain, reducing the need for future investments in expensive in-service training [23]. Pre-service training is an effective way of introducing principles and practices of health commodities supply chain management [19].

The reliability analysis revealed an average mean \pm standard deviation score (3.1753 \pm 1.0757) for progress in capacity building, indicating sample progress has been made in the capacity building of the HIV/AIDS supply chain workforce. Factor loading ranged from (0.574-0.865), which is good and entails all mean components are added to the summation. Cronbach's alpha, $\alpha=0.237$, showed the questionnaire is less reliable.

Inferential statistics revealed that sociodemographic characteristics such as age, sex, years of experience, educational qualification, and job title/rank have no effect on the extent of 
progress in capacity building of the HIV/AIDS supply chain workforce ( $\mathrm{P}>0.05)$.

There was a relationship between progress in capacity building and HIV/AIDS supply chain workforce capacity $\mathrm{P}<0.05$. Also, the extent of progress in capacity building of the supply chain workforce is a significant factor of HIV/AIDS supply chain workforce capacity.

Table 1. Socio-demographic Characteristics of Participants

\begin{tabular}{|l|l|l|}
\hline Characteristics & Categorization $(\mathbf{N}=396)$ & Number (\%) \\
\hline \multirow{4}{*}{ Age (Years) } & $30-49$ & $328(82.9)$ \\
\cline { 2 - 3 } Gender & $50-\geq 60$ & $68(17.1)$ \\
\hline \multirow{4}{*}{ Years of Experience } & Female & $121(30.6)$ \\
\cline { 2 - 3 } & Male & $275(69.4)$ \\
\hline \multirow{5}{*}{$\begin{array}{l}\text { Highest Educational of Engagement } \\
\text { Qualification }\end{array}$} & $0-7$ & $138(34.9)$ \\
\cline { 2 - 3 } & $\geq 16$ & $241(60.8)$ \\
\cline { 2 - 3 } & Public & $17(4.3)$ \\
\cline { 2 - 3 } & Private & $103(26.0)$ \\
\cline { 2 - 3 } & Non-governmental Organization & $207(52.3)$ \\
\cline { 2 - 3 } & Donor Agency & $17(4.3)$ \\
\cline { 2 - 3 } & Bachelors/Postgraduate Diploma & $133(33.6)$ \\
\cline { 2 - 3 } & Fellowship/Master's Degree & $256(64.6)$ \\
\hline
\end{tabular}

Table 2. Percentage Frequency of Progress in Capacity Building of HIV/AIDS Supply Chain Workforce $(\mathrm{N}=396)$

\begin{tabular}{|l|l|}
\hline Items & Positive Responses \\
\cline { 2 - 2 } & Frequency N (\%) \\
\hline Training need assessment is always conducted before trainings are conducted & $104(26.3)$ \\
\hline $\begin{array}{l}\text { Donor Agencies intervention has contributed considerably to capacity building of } \\
\text { Government personnel across all levels and there is adequate capacity at the national level } \\
\text { especially within the Donor Agencies, NGOs and private sector }\end{array}$ & $396(100.0)$ \\
\hline There is adequate pool of master trainers in HIV/AIDS supply chain system & $155(39.1)$ \\
\hline Fellowship training program aimed at enhancing leadership and management capacity & $189(47.7)$ \\
\hline $\begin{array}{l}\text { Master trainers from government are always part of the facilitators and involved in the } \\
\text { implementation of capacity building interventions }\end{array}$ & $103(26.0)$ \\
\hline $\begin{array}{l}\text { Personnel in Nigeria HIV/AIDS supply chain have demonstrated capacity to some extent } \\
\text { in the key supply chain functions }\end{array}$ & $259(65.4)$ \\
\hline $\begin{array}{l}\text { HIV/AIDS supply chain capacity development has been institutionalized at national, state } \\
\text { and LGA levels through National Product Supply Chain Management Programme } \\
\text { (NPSCMP), Procurement and Supply Management Technical Working Groups (PSM } \\
\text { TWGs) and Logistics Management Coordinating Unit (LMCU) }\end{array}$ & $292(73.7)$ \\
\hline $\begin{array}{l}\text { Pre-service training has been institutionalized in the schools of Pharmacy, Laboratory } \\
\text { Sciences and Health Technology to address competency gaps }\end{array}$ & $190(48.0)$ \\
\hline
\end{tabular}

Positive Responses $=$ Agree/ Strongly Agree 
Table 3. Reliability Analysis of Progress in Capacity Building of HIV/AIDS Supply Chain Workforce (N= 396)

\begin{tabular}{|c|c|c|c|c|}
\hline Items & Mean & SD & Factor Loading & Cronbach's Alpha \\
\hline $\begin{array}{l}\text { Training need assessment is always } \\
\text { conducted before trainings are conducted }\end{array}$ & 2.659 & 1.2044 & 0.813 & 0.237 \\
\hline $\begin{array}{l}\text { Donor Agencies intervention has } \\
\text { contributed considerably to capacity } \\
\text { building of Government personnel across } \\
\text { all levels and there is adequate capacity } \\
\text { at the national level especially within the } \\
\text { Donor Agencies, NGOs and private } \\
\text { sector }\end{array}$ & 4.437 & 0.4966 & 0.618 & \\
\hline $\begin{array}{l}\text { There is adequate pool of master trainers } \\
\text { in HIV/AIDS supply chain system }\end{array}$ & 2.614 & 1.2787 & 0.804 & \\
\hline $\begin{array}{l}\text { Fellowship training program aimed at } \\
\text { enhancing leadership and management } \\
\text { capacity }\end{array}$ & 3.005 & 1.2180 & 0.865 & \\
\hline $\begin{array}{l}\text { Master trainers from government are } \\
\text { always part of the facilitators and } \\
\text { involved in the implementation of } \\
\text { capacity building interventions }\end{array}$ & 2.596 & 1.2069 & 0.830 & \\
\hline $\begin{array}{l}\text { Personnel in Nigeria HIV/AIDS supply } \\
\text { chain have demonstrated capacity to } \\
\text { some extent in the key supply chain } \\
\text { functions }\end{array}$ & 3.217 & 1.1016 & 0.831 & \\
\hline $\begin{array}{l}\text { HIV/AIDS supply chain capacity } \\
\text { development has been institutionalized at } \\
\text { national, state and LGA levels through } \\
\text { National Product Supply Chain } \\
\text { Management Programme (NPSCMP), } \\
\text { Procurement and Supply Management } \\
\text { Technical Working Groups (PSM TWGs) } \\
\text { and Logistics Management Coordinating } \\
\text { Unit (LMCU) }\end{array}$ & 3.912 & 0.9781 & 0.574 & \\
\hline $\begin{array}{l}\text { Pre-service training has been } \\
\text { institutionalized in the schools of } \\
\text { Pharmacy, Laboratory Sciences and } \\
\text { Health Technology to address } \\
\text { competency gaps }\end{array}$ & 2.962 & 1.1211 & 0.831 & \\
\hline Mean of mean \pm SD & 3.175 & 1.0757 & & \\
\hline
\end{tabular}


Table 4. Effect of Socio-demographic Characteristics on Progress in Capacity Building (N=396)

\begin{tabular}{|l|l|l|}
\hline Variables & N & Progress in Capacity Building \\
\hline Age & 121 & $3.218 \pm 1.0803$ \\
\hline Below 40 & 275 & $3.156 \pm 1.0732$ \\
\hline Above 40 & 0.5974 \\
\hline P-value & 275 & $3.177 \pm 1.0668$ \\
\hline Sex & 121 & $3.171 \pm 1.0954$ \\
\hline Male & 0.9592 \\
\hline Female & \\
\hline P-value & 138 & $3.183 \pm 1.0619$ \\
\hline Years of experience & 258 & $3.171 \pm 1.0821$ \\
\hline Below 8 & 0.9157 \\
\hline Above 8 & \\
\hline P-value & 119 & $3.165 \pm 1.0827$ \\
\hline Highest Education & 277 & $3.180 \pm 1.0729$ \\
\hline Bachelor's Degree & 0.8517 \\
\hline Postgraduate & \\
\hline p-value & $3.170 \pm 1.0718$ \\
\hline Job Titles & $3.185 \pm 1.0825$ \\
\hline Managers/Directors & 258 & 0.8656 \\
\hline Specialists/Advisors & 138 & \\
\hline P-value &
\end{tabular}

Table 5. Relationship between Progress in Capacity Building and HIV/AIDS Supply Chain Workforce Capacity $(\mathrm{N}=396)$

\begin{tabular}{|l|l|l|l|l|l|}
\hline \multirow{2}{*}{$\begin{array}{l}\text { Progress in Capacity } \\
\text { Building }\end{array}$} & \multicolumn{2}{|l|}{ Factors of Supply Chain Workforce Capacity } & \multirow{2}{*}{ Total } & \multirow{2}{*}{$\chi^{2}$} & \\
\cline { 2 - 5 } & High Level Factors (\%) & Low Level Factors (\%) & & \\
\hline High Level of Progress & $201(72.8)$ & $75(27.2)$ & $276(100.0)$ & \multirow{2}{*}{95.1} & \\
\hline Low Level of Progress & $24(20.0)$ & $96(80.0)$ & $120(100.0)$ & & \\
\hline
\end{tabular}

Null Hypothesis $\left(\mathbf{H}_{\mathbf{0}}\right.$ : : Progress in capacity building is not a significant factor of HIV/AIDS supply chain workforce capacity

Alternative Hypothesis $\left(\mathbf{H}_{\mathbf{a}) \text { : }}\right.$ Progress in capacity building is a significant factor of HIV/AIDS supply chain workforce capacity

\section{Conclusion}

The study revealed substantial progress in capacity building of HIV/AIDS supply chain workforce and includes adequate supply chain capacity at the national level especially within the donor agencies, non-governmental organizations, and private sector, institutionalization of supply chain capacity development at all level of the health sector through the creation of supply chain management coordination structures and demonstrable capacity in key supply chain functions among HIV/AIDS supply chain workforce. Also, master trainers from the government are not always part of the facilitators and are involved in the implementation of capacity-building interventions, and training needs assessment does not always precede training, an inadequate pool of master trainers, non-recognition of the fellowship program and pre-service training has not been institutionalized. 


\section{Recommendations}

Federal and State Ministries of Health should rise to the responsibility of playing an active and leading role in the HIV/AIDS supply chain workforce capacity development programs, include master trainers from the government in the implementation of capacity building activities, institutionalize pre-service training and make sure need assessment precedes capacity building interventions. More so, conduct more training to ensure a sufficient pool of master trainers within the public sector that can drive the country's HIV/AIDS supply

\section{References}

[1] IOM (Institute of Medicine), 2011, Preparing for the Future of HIV/ AIDS in Africa: A Shared Responsibility. Washington, DC: The National Academies

Press. https://www.ncbi.nlm.nih.gov/books/NBK209740/.

[2] WHO Drug Action Program, 1998, (http://www.who.int/medicinedocs/collect/medicine docs/pdf/s2237e/s2237e.pdf).

[3] WHO, 2007, Everybody's business: Strengthening health systems to improve health outcomes: WHO's framework for action, WHO

Document Production Services, Geneva, Switzerland,

https://www.who.int/healthsystems/strategy/everybo dys_business.pdf.

[4] Frenk, J., 2010, The Global Health System: Strengthening National Health Systems as the Next Step for Global Progress. PLoS Med, 7(1): e1000089,

https://doi.org/10.1371/journal.pmed.1000089.

[5] United States Agency for International Development (USAID), 2015a, USAID's vision for health systems strengthening. Washington, DC, USA,

https://www.usaid.gov/sites/default/files/documents/ 1864/HSS-Vision.pdf.

[6] Adeloye, D., David, R. A., Olaogun, A. A., Auta, A., Adesokan, A., Gadanya, M., Opele, J. K., Owagbemi, O., and Iseolorunkanmi, A., 2017, chain functions which is fundamental for progress, ownership, and sustainability.

\section{Acknowledgements}

The authors are grateful to the study participants for providing relevant information that ensured the successful completion of this research

\section{Conflicts of Interest}

The authors declare no conflicts of interest exist.

Health workforce and governance: the crisis in Nigeria, Human Resources for Health, 15:32, https://human-resources-

health.biomedcentral.com/articles/10.1186/s12960-

017-0205-4.

[7] WHO, 2016, Nigeria. In: Global Health Workforce Alliance. Geneva, Switzerland, https://www.who.int/workforcealliance/countries/ng a/en/.

[8] Dal Poz, M. R., Gupta, N., Quain, E. and Soucat, A. L. B., 2009, Handbook on monitoring and evaluation of human resources for health. Geneva, WHO

Press, https://www.who.int/hrh/resources/handbook/en/ [9] WHO, 2010, Growing threat from counterfeit medicines. Bulletin, 88(4):241-320, https://www.who.int/bulletin/volumes/88/4/10020410/en/

[10]Hyder, A. A, Bloom, G., Leach, M., Syed, S. B., Peters, D. H. and Future Health Systems: Innovations for Equity, 2007, "Exploring health systems research and its influence on policy processes in low- income countries". BMC Public Health, 7:309, https://bmcpublichealth.biomedcentral.com/articles/ 10.1186/1471-2458-7-309.

[11]David, P. and Bennet, S., 2012, "Better Guidance Is Welcome, but without Blinders". PLoS Med 9 (3): e1001188, https://doi.org/10.1371/journal.pmed.1001188\. 
[12]Bennet, S., Agyepong, I. A., Sheikh, K., Hanson, K., Ssengooba, F. and Gilson, L., 2011, "Building the Field of Health Policy and Systems Research: An Agenda for Action". PLoS Medicine. 8 (8): e1001081.doi:10.1371/journal.pmed.1001081, https://pubmed.ncbi.nlm.nih.gov/21918641/.

[13] Campbell, J., Cometto, G., Rasanathan, K., Kelley, E., Syed, S., Zurn, P., De Bernis, L., Matthews, Z., Benton, D., Frank, O. and Nove, A., 2015, Improving the resilience and workforce of health systems for women's, children's, and adolescents' health. BMJ, 351:h4148, https://pubmed.ncbi.nlm.nih.gov/26371216/.

[14] Aondoakaa, S.C. and Agbakwuru, P.C., 2012, An Assessment of land Suitability for Rice Cultivation in Dobi, Gwagwalada Area Council, FCT, Nigeria. Ethiopian Journal of Environmental Studies and Management, 5(4):559-566, https://dx.doi.org/10.4314/ejesm.v5i4.S2.

[15] Ebele, F.U., Aregbosola, B.G., Hasstrup, D.T. and Adams, E., 2014, The Effect of Climate Change on Agricultural Production among Farmers in Kwali Area Council of Federal Capital Territory of Nigeria. Advances in Social Sciences Research Journal,

$1(2): 13-26$, https://doi.org/10.14738/assrj.12.58.

[16]Cochran, W.G., 1977, Sampling Techniques. 3rd Edition, John Wiley \& Sons, New York, https://archive.org/details/Cochran1977SamplingTec hniques_201703.

[17] Itiola, A. J., and Agu, K. A., 2018, Country ownership and sustainability of Nigeria's HIV/AIDS Supply Chain System: qualitative perceptions of progress, challenges and prospects. Journal of Pharmaceutical Policy and Practice, 11:21, https://joppp.biomedcentral.com/articles/10.1186/s4 0545-018-0148-8.

[18] Goldberg, J. and Bryant, M., 2012, Country ownership and capacity building: the next buzzwords in health systems strengthening or a truly new approach to development? BMC Public Health, 12:531-539,

https://pubmed.ncbi.nlm.nih.gov/22818046/.

[19] Machagge, M., Matoyo, D. and Alenga, I., 2014, Supply chain management curriculum integration in pre-service training in Tanzania. Journal of Pharmaceutical Policy and Practice, 7(Suppl 1): P14, https://joppp.biomedcentral.com/articles/10.1186/20 52-3211-7-S1-P14.

[20] Matovu, J. K. B., Rhoda, K. W., Susan M., Olico O., William, B. and David S., 2013, Strengthening health workforce capacity through work-based training; BMC International Health and Human Rights, 13:8, https://bmcinthealthhumrights.biomedcentral.com/ar ticles/10.1186/1472-698X-13-8.

[21] Windisch, R., Waiswa, P., Neuhann, F., Scheibe, F. and Savigny, D., 2011, Scaling up antiretroviral therapy in Uganda: using supply chain management to appraise health systems strengthening. Globalization and Health, 7:25, https://europepmc.org/article/PMC/3161852.

[22] Adekola, A. and Adelanwa, A., 2014, Developing the SCM workforce in Nigeria through contextualized pre-service education and continued professional development. Journal of Pharmaceutical Policy and Practice, 7(Suppl 1): $\mathrm{O} 22$ https://joppp.biomedcentral.com/articles/10.1186/20 52-3211-7-S1-O22.

[23] Mazibuko, G. N., Sagwa, E., Kagoya, H. R., Kibuule, D., Rennie, T., Mavere, T., Ghoneim, R., Mabirizi, D., Naikaku, E., Niaz, Q. and Lates, J., 2014, Incorporating pharmaceutical supply management modules in the pre-service curriculum of the BPharm program, of the University of Namibia, School of Pharmacy, Journal of Pharmaceutical Policy and Practice, 7(Suppl 1): P12, http://www.joppp.org/supplements/7/S1. 